ISSN 0103-9954

\title{
CLASSIFICAÇÃO DA VEGETAÇÃO SECUNDÁRIA EM ESTÁGIOS DE REGENERAÇÃO DA MATA ATLÂNTICA EM SANTA CATARINA
}

\author{
CLASSIFICATION OF SECONDARY FORESTS IN REGENERATION STAGES OF 'MATA \\ ATLÂNTICA' FOREST, IN SANTA CATARINA STATE, BRAZIL
}

\author{
Alexandre Siminski ${ }^{1}$ Alfredo Celso Fantini ${ }^{2}$ Mauricio Sedrez Reis ${ }^{3}$
}

\begin{abstract}
RESUMO
Este estudo teve por objetivo determinar critérios e parâmetros para o inventário e classificação das formações secundárias no estado de Santa Catarina. Foram realizados inventários florestais em 160 parcelas em quatro diferentes estágios de sucessão natural, em todas as formações florestais do Estado. Entre os resultados, propõe-se que os inventários, para fins de classificação, incluam todos os indivíduos da parcela que tenham $\geq 5 \mathrm{~cm}$ de DAP e que a área basal seja a pricipal variável analizada para a classificação da formação vegetal em estádios sucessionais. Também propõe-se a reavaliação dos parâmetros definidos pela atual Resolução.
\end{abstract}

Palavras-chave: inventário florestal; regeneração natural; legislação florestal.

\begin{abstract}
This study was designed to determine the criteria and the parameters needed for the inventory and the classification of the secondary forest in the Atlantic coast of Santa Catarina state, in Brazil. The forest inventories were conducted in 160 plots at four different stages of natural succession, in all forest of the state. It is proposed that inventories needed for the legal classification of secondary forests should include all individuals of each plot $\geq 5 \mathrm{~cm}$ DBH and that basal area should be the central variable used to assign these forest formations in successional stages. This study also suggests the need to review the current regulation parameters in this place for the forest classification of Mata Atlântica defined by the current resolution.
\end{abstract}

Keywords: forest inventory; forest succession; forest legislation.

\section{INTRODUÇÃO}

A definição do estágio sucessional de uma formação florestal na região da Mata Atlântica tem implicações nas possibilidades de uso da terra e, consequentemente, na economia e na política ambiental. Uma vez que os estágios sucessionais são mencionados nos textos das leis de proteção ambiental, a exemplo da Lei da Mata Atlântica (Lei n ${ }^{\circ}$ 11.428/2006) (BRASIL, 2006), torna-se necessário definir critérios técnicos que permitam objetivamente diferenciá-los e classificá-los.

Existe um grande número de trabalhos científicos que abordam o processo de sucessão secundária através dos estágios de regeneração em florestas tropicais (FINEGAN, 1996; WHITMORE, 1998; GUARIGUATA e OSTERTAG, 2001; VAN BREUGEL, 2007), no Bioma Mata Atlântica (DRUMOND e NETO, 1999; TABARELLI e MANTOVANI 1999; OLIVEIRA, 2002; ALVES e METZGER, 2006; OLIVEIRA et al., 2006; LIEBSCH et al., 2007; RAMOS e BOLDO, 2007; LIEBSCH et al., 2008; LANA et al., 2010), e em Santa Catarina (KLEIN, 1980; QUEIROZ, 1994; SIMINSKI et al. 2004, MANTOVANI et al. 2005; SCHORN e GALVÃO, 2006; SCHUCH, 2010; SIMINSKI et al. 2011).

Os trabalhos citados anteriormente têm apresentado a diversidade de fatores que influenciam o processo de sucessão, entre os quais estão

1 Engenheiro Agrônomo, Dr., Professor da Universidade Federal de Santa Catarina, Campus Curitibanos, Rodovia Ulisses Gaboardi, km 3, CEP 89520-000, Curitibanos (SC). alexandre.siminski@ufsc.br.

2 Engenheiro Agrônomo, Dr., Professor da Universidade Federal de Santa Catarina, Centro de Ciências Agrárias, Rodovia Admar Gonzaga, 1346, Itacorubi, CEP 88034-000, Florianópolis (SC). afantini@cca.ufsc.br.

3 Engenheiro Agrônomo, Dr., Professor da Universidade Federal de Santa Catarina, Centro de Ciências Agrárias, Rodovia Admar Gonzaga, 1346, Itacorubi, CEP 88034-000, Florianópolis (SC). msedrez@gmail.com Recebido para publicação em 5/01/2011 e aceito em 30/09/2011 
o histórico de uso da área, o nível de pertubação ao qual foi submetida, as condições químicas e físicas do solo, o clima da região, o estoque do banco de sementes do solo, a paisagem do entorno e a interação entre as espécies. A combinação desses atributos do ecossistema confere ao processo de sucessão uma complexidade que torna difícil a sua adequada representação, mesmo através da combinação de diferentes critérios.

Diversas características e metodologias têm sido usadas para diferenciar estágios sucessionais: (1) idade da vegetação (SALDARRIAGA et al., 1988; UHL et al., 1988); (2) parâmetros estruturais (MORAN e BRONDÍZIO, 1998; JASTER, 2002; SIMINSKI e FANTINI, 2004); (3) características fitofisionômicas (KLEIN, 1980; QUEIROZ, 1994; LANA et al., 2010); (4) sensoriamento remoto (MAUSEL et al., 1993; CINTRA et al. 2007; AMARAL et al., 2009) e, (5) análises multivariadas (FONSECA e FONSECA, 2004; SILVA, et al., 2004).

A maior parte destes trabalhos tem como foco a caracterização do processo ecológico da sucessão natural, entretanto, poucos têm relacionado este processo às exigências legais de caracterização dos estágios de regeneração da floresta. Em Santa Catarina, a definição dos estágios de regeneração foi estabelecida através da Resolução no 04/1994 do Conselho Nacional do Meio Ambiente (CONAMA, 1994), convalidada pela Resolução $n^{\circ} 388 / 2007$ (CONAMA, 2007), em atendimento às exigências estabelecidas inicialmente através do Decreto Federal no 750/1993 (BRASIL, 1993) revogado em 2008 quando houve a regulamentação da Lei da Mata Atlântica (BRASIL, 2008). A Resolução determina a observação de um conjunto de critérios e indicadores qualitativos e quantitativos (estruturais) para a caracterização da vegetação primária e secundária nos estádios inicial, médio e avançado de regeneração.

No entanto, a falta de normatização para a amostragem da vegetação, principalmente no que diz respeito ao inventário florestal exigido para esta caracterização, fragiliza e compromete os valores limites das variáveis estabelecidos pela resolução para diferenciar os estágios de regeneração (SIMINSKI e FANTINI, 2004). Adicionalmente, pesquisadores, técnicos e agricultores argumentam que os parâmteros definidos na atual resolução foram estabelecidos sem base em um estudo aprofundado sobre o processo de sucessão florestal, além de desconsiderar os possíveis impactos sobre o modo de vida e siste- ma produtivo das populações humanas diretamente relacionadas com estes recursos (SIMINSKI, 2009).

Neste contexto, esse trabalho objetiva definir critérios para a normatização do inventário florestal e para a readequação dos parâmetros da legislação pertinente utilizados para a classificação da vegetação secundária em estágios de regeneração em Santa Catarina.

\section{MATERIAL E MÉTODOS}

\section{Localização das áreas}

O trabalho foi executado em 48 propriedades agrícolas distribuídas em seis municípios do estado de Santa Catarina, representando, dois municípios em cada uma das três unidades fitogeográficas existentes: Floresta Ombrófila Mista (Três Barras e Caçador), Floresta Estacional Decidual (Anchieta e Concórdia) e Floresta Ombrófila Densa (Garuva e São Pedro de Alcântara). Adicionalmente, foi inventariada uma área dentro do Parque Estadual Fritz Plaumann no município de Concórdia (Figura 1).

\section{Coleta dos dados}

Foram amostradas 160 áreas onde os diferentes estágios da sucessão fossem identificáveis, através das características fitofisionômicas (KLEIN, 1980) e de informações dos proprietários (idade, uso da terra, ciclos de cultivo). Foram caracterizados quatro estágios sucessionais com base na fitofisionomia da vegetação, conforme proposto por Siminski (2009): 1) estágio Arbustivo; 2) estágio de Arvoretas; 3) estágio Arbóreo Pioneiro e; 4) estágio Arbóreo Avançado.

Em cada área selecionada, foi implantada uma parcela na parte central do bloco de vegetação com as mesmas características fitofisionômicas. Foram levantadas 60 parcelas de 10 x 10 metros e 100 parcelas de $20 \times 10$ metros, totalizando uma área amostrada de $26.000 \mathrm{~m}^{2}$. Cada parcela avaliada foi considerada como uma repetição para o respectivo estágio sucessional, e cada estágio teve pelo menos 30 repetições. Nas parcelas, foram mensurados todos os indivíduos arbustivos e arbóreos maiores que 1,5 metros de altura, sendo obtidos o diâmetro a altura do peito (DAP), a altura total (AT) e a identificação taxonômica. A mensuração do diâmetro foi feita com o auxílio de suta florestal $(80 \mathrm{~cm})$, enquanto as alturas foram obtidas com o auxílio de régua dendrométrica e avaliação visual. A identifi- 


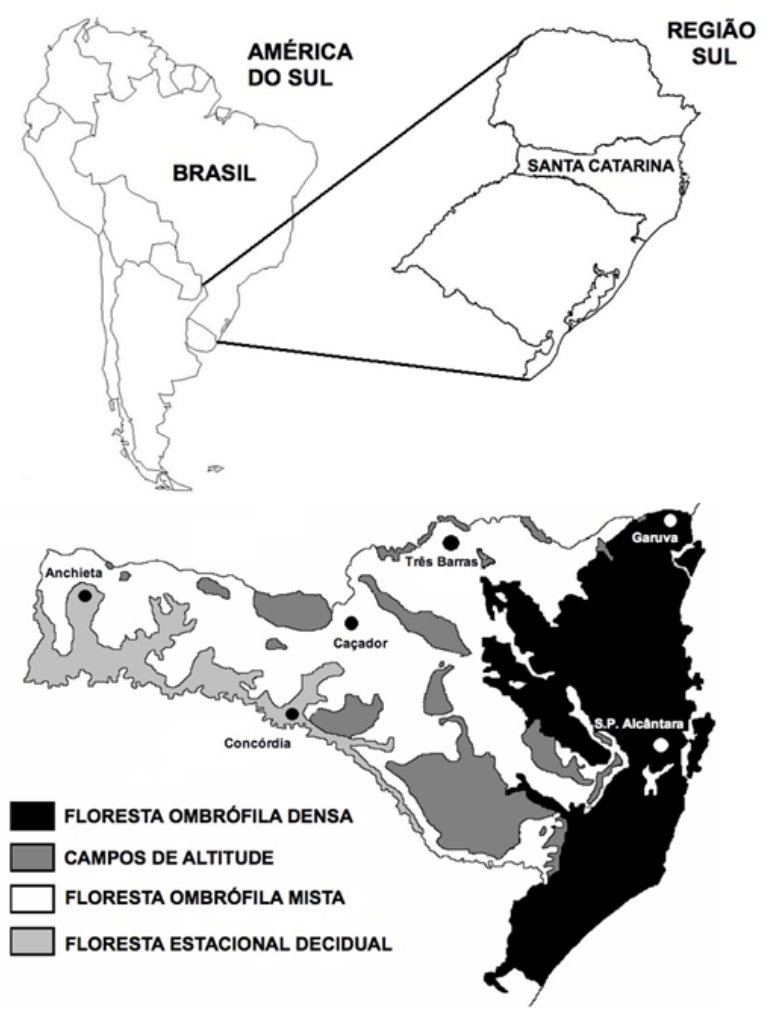

FIGURA 1: Localização das áreas de estudo nas tipologias florestais conforme ilustradas no Mapa fitogeográfico do estado de Santa Catarina (adaptado de KLEIN, 1978).

FIGURE 1: Location of study areas in forest types as illustrated in Santa Catarina phytogeographic map (adapted from KLEIN, 1978).

cação taxonômica foi realizada em campo, quando inequívoca. Nos casos de dúvida, foi procedida a coleta de material botânico e posterior confecção de exsicatas compostas de partes vegetativas e/ou reprodutivas. Nesse caso, a identificação foi feita com auxílio de bibliografia especializada (diversos volumes da Flora Ilustrada Catarinense), e confirmadas pelo Prof. Dr. Ademir Reis e pelo pesquisador Dr. Ademir Roberto Ruschel, seguindo o sistema do Angiosperm Phylogeny Group APG II (2003). As exsicatas foram depositadas no acervo do Núcleo de Pesquisas em Florestas Tropicais-UFSC e a relação de espécies está disponível em Siminski et al. (2011).

\section{Análise dos dados}

A partir dos dados de cada planta avaliada, foram calculadas as médias aritméticas das variáveis DAP e AT, e estimada a área basal por hectare
$(\mathrm{AB})$ e o número de indivíduos por hectare (Ind/ha) de cada uma das parcelas. A análise dos dados foi efetuada através de análise da variância (ANOVA) segundo Sokal e Rohlf (1995), através do programa STATGRAFICS 7.0 (Manugistic Inc. USA). Quando foram detectadas diferenças significativas, a comparação entre médias foi realizada pelo teste de SNK a 5\% de probabilidade.

$\mathrm{O}$ diâmetro a altura do peito (DAP) foi utilizado como a variável para a definição dos indivíduos a serem medidos nas unidades amostrais (SIMINSKI e FANTINI, 2004). Uma vez definido o DAP como variável de trabalho, foi realizada uma série de simulações que consideraram diferentes valores de limite inferior dessa variável como critério para amostragem e seu impacto na classificação das formações secundárias. Foram comparados quatro valores de DAP $(\mathrm{cm})$ mínimo para inclusão dos indivíduos na amostra: $>0 \mathrm{~cm}$ (onde foram mensurados todos os indivíduos da parcela que apresentavam altura suficiente para medição do DAP); $\geq$ $3 \mathrm{~cm} ; \geq 5 \mathrm{~cm}$ e $\geq 10 \mathrm{~cm}$.

\section{RESULTADOS E DISCUSSÃO}

\section{Definição do critério de amostragem}

Foi observada uma grande variação nos resultados da classificação da vegetação em estágios sucessionais em função do diâmetro mínimo usado para inclusão dos indivíduos na amostra (Tabela 1). A primeira implicação foi a redução do número de indivíduos a serem avaliados a medida que o DAP mínimo para inclusão na amostra é maior. No estágio arbustivo, a diferença do número de plantas a serem medidas é de cinquenta vezes, entre incluir todos os indivíduos da parcela ou somente aqueles com DAP maior ou igual a $10 \mathrm{~cm}$. As diferenças são reduzidas proporcionalmente nos estágios subsequentes.

A estimativa do DAP médio, sugerida pela resolução do CONAMA, foi a variável de mensuração mais sensível a diferentes diâmetros mínimos de inclusão na amostra para todos os estágios, sendo observada diferença estatisticamente significativa do DAP médio resultante da parcela como função do diâmetro mínimo (Tabela 1). O DAP médio resultante aumentou de três a cinco vezes quando o diâmetro de inclusão passou de $0 \mathrm{~cm}$ para $10 \mathrm{~cm}$.

Para a altura média da parcela, verificou-se que o valor dobra quando se comparam as amostras que incluem plantas com diâmetro maior ou igual 
TABELA 1: Valores do diâmetro a altura do peito (DAP) médio, altura total média, área basal (AB) e densidade (Número de indivíduos por hectare) em quatro estágios sucessionais da Mata Atlântica em Santa Catarina, considerando-se diferentes diâmetros mínimos para a amostragem dos indivíduos.

TABLE 1: Diameter values at breast height (DBH), total mean height, basal area and density (number of individual per hectare) for four different successional stages in 'Mata Atlântica' forest, in Santa Catarina state, considering different minimum diameter to the sampling.

\begin{tabular}{|c|c|c|c|c|c|}
\hline $\begin{array}{l}\text { Estágio de } \\
\text { Sucessão }\end{array}$ & $\begin{array}{l}\text { Diâmetro de inclusão } \\
\qquad(\mathrm{cm})\end{array}$ & $\begin{array}{l}\text { DAP médio } \\
\quad(\mathrm{cm})\end{array}$ & $\begin{array}{l}\text { Altura } \\
\text { total média }{ }^{(1)} \\
(\mathrm{m})\end{array}$ & $\begin{array}{c}\text { Área basal } \\
\mathrm{m}^{2} / \mathrm{ha}\end{array}$ & $\begin{array}{l}\text { Densidade }^{(1)} \\
\text { ind } / \text { ha }\end{array}$ \\
\hline \multirow{4}{*}{ Arbustivo } & $>0 \mathrm{~cm}$ & $2,3 \mathrm{a}$ & $2,9 \mathrm{a}$ & $5,9 \mathrm{a}$ & $8.560 \mathrm{a}$ \\
\hline & $\geq 3 \mathrm{~cm}$ & $4,6 \mathrm{~b}$ & $3,9 \mathrm{~b}$ & $3,8 \mathrm{~b}$ & $1.844 \mathrm{~b}$ \\
\hline & $\geq 5 \mathrm{~cm}$ & $6,5 \mathrm{c}$ & $4,4 \mathrm{~b}$ & $2,3 \mathrm{bc}$ & $711 \mathrm{c}$ \\
\hline & $\geq 10 \mathrm{~cm}$ & $12,1 \mathrm{~d}$ & $5,9 \mathrm{c}$ & $1,7 \mathrm{c}$ & $172 \mathrm{c}$ \\
\hline \multirow{4}{*}{ Arvoretas } & $>0 \mathrm{~cm}$ & $3,9 \mathrm{a}$ & $4,1 \mathrm{a}$ & $13,3 \mathrm{a}$ & $8.131 \mathrm{a}$ \\
\hline & $\geq 3 \mathrm{~cm}$ & $6,2 \mathrm{~b}$ & $5,4 \mathrm{~b}$ & $11,6 \mathrm{ab}$ & $3.148 \mathrm{~b}$ \\
\hline & $\geq 5 \mathrm{~cm}$ & $8,1 \mathrm{c}$ & $6,0 \mathrm{~b}$ & $10,0 \mathrm{~b}$ & $1.573 \mathrm{c}$ \\
\hline & $\geq 10 \mathrm{~cm}$ & $12,9 \mathrm{~d}$ & $7,1 \mathrm{c}$ & $5,0 \mathrm{c}$ & $300 \mathrm{c}$ \\
\hline \multirow{4}{*}{ Arbóreo Pioneiro } & $>0 \mathrm{~cm}$ & $5,0 \mathrm{a}$ & $5,0 \mathrm{a}$ & $26,1 \mathrm{a}$ & $7.694 \mathrm{a}$ \\
\hline & $\geq 3 \mathrm{~cm}$ & $8,0 \mathrm{~b}$ & $6,8 \mathrm{~b}$ & $25,5 \mathrm{a}$ & $3.743 \mathrm{~b}$ \\
\hline & $\geq 5 \mathrm{~cm}$ & $10,2 \mathrm{c}$ & $7,9 \mathrm{c}$ & $23,4 \mathrm{a}$ & $2.341 \mathrm{c}$ \\
\hline & $\geq 10 \mathrm{~cm}$ & $15,8 \mathrm{~d}$ & $9,8 \mathrm{~d}$ & $18,6 \mathrm{a}$ & $821 \mathrm{~d}$ \\
\hline \multirow{4}{*}{ Arbóreo Avançado } & $>0 \mathrm{~cm}$ & $6,5 \mathrm{a}$ & $5,7 \mathrm{a}$ & $40,2 \mathrm{a}$ & $6.870 \mathrm{a}$ \\
\hline & $\geq 3 \mathrm{~cm}$ & $10,0 \mathrm{~b}$ & $7,9 \mathrm{~b}$ & $38,7 \mathrm{ab}$ & $3.201 \mathrm{~b}$ \\
\hline & $\geq 5 \mathrm{~cm}$ & $12,7 \mathrm{c}$ & $9,1 \mathrm{c}$ & $35,4 \mathrm{ab}$ & $2.237 \mathrm{c}$ \\
\hline & $\geq 10 \mathrm{~cm}$ & $18,1 \mathrm{~d}$ & $11,2 \mathrm{~d}$ & $33,2 \mathrm{~b}$ & $1.080 \mathrm{~d}$ \\
\hline \multicolumn{2}{|c|}{$\begin{array}{l}\text { Estágio de regeneração segundo a } \\
\text { Resolução n04/1994 do CONAMA }\end{array}$} & $\begin{array}{l}\text { DAP médio } \\
(\mathrm{cm})\end{array}$ & $\begin{array}{l}\text { Altura média } \\
(\mathrm{m})\end{array}$ & $\begin{array}{c}\text { Área basal } \\
\mathrm{m}^{2} / \mathrm{ha}\end{array}$ & $\begin{array}{c}\text { Densidade }^{(2)} \\
\text { ind/ha }\end{array}$ \\
\hline \multicolumn{2}{|c|}{ inicial } & até 8 & até 4 & até 8 & - \\
\hline \multicolumn{2}{|c|}{ médio } & até 15 & até12 & até 15 & - \\
\hline \multicolumn{2}{|c|}{ avançado } & até 25 & até 20 & até 20 & - \\
\hline
\end{tabular}

(1) $\mathrm{Na}$ vertical, dentro de um mesmo estágio, valores com a mesma letra não diferem entre si ao nível de $5 \%$ de probabilidade de erro pelo teste SNK. (2)A Resolução n04/1994 do CONAMA não apresenta valores para densidade de indivíduos.

a $0 \mathrm{~cm}$ e $10 \mathrm{~cm}$, respectivamente. Por sua vez, a área basal sofre redução quando se aumenta o diâmetro mínimo de inclusão na amostra. Nos estágios Arbustivo e das Arvoretas, a redução é de três vezes entre os extremos de 0 e $10 \mathrm{~cm}$ de diâmetro como critério de inclusão, mas significativamente menor para os estágios mais avançados da sucessão. Nestes estágios, há uma diferença relativamente menor entre o número de indivíduos amostrados para cada categoria de inclusão na amostra e uma contribuição proporcionalmente maior dos indivíduos de maior porte para o composição da área basal (Tabela 1).

De acordo com os critérios para definição dos estágios de regeneração propostos pela Resolução $n^{\circ}$ 04/1994 do CONAMA esperava-se uma correspondência entre os estágios da sucessão natural levantados com a Resolução, que seria: 1) enquadrar o estágio Arbustivo como estágio Inicial de regeneração; 2) o estágio de Arvoretas como estágio Médio de regeneração e; 3) os estágios Arbóreo Pioneiro e Arbóreo Avançado como estágios Avançado de regeneração.

Os resultados da Tabela 1 demonstram a dificuldade de se obter correspondência entre as duas classificações, independente do critério de DAP adotado no inventário florestal. Novamente, os parâmetros que representam o valor médio dos indivíduos de uma parcela (DAP e altura total), não são boas referências para a caracterização dos estágios, especialmente por serem altamente influenciados pela escolha do diâmetro mínimo adotado na amostragem.

A variação dos dados obtidos através do inventário florestal acaba refletindo em uma dificuldade de enquadramento dos estágios da sucessão 
natural dentro de um único estágio de regeneração propostos pela Resolução n ${ }^{\circ}$ 04/1994 do CONAMA, através dos valores que os caracterizam. Os resultados reforçam a necessidade de se definir um diâmetro mínimo para inclusão de plantas na amostra do inventário para fins de classificação da vegetação em estágios de sucessão, o que corrobora o estudo preliminar realizado por Siminski e Fantini (2004). A falta de um critério permite que áreas com características fitofisionômicas semelhantes possam ser enquadradas em estágios de regeneração diferentes, dependendo do critério adotado no inventário florestal (SIMINSKI, 2009).

Os dados sugerem que a inclusão de todos os indivíduos (DAP $\geq 0 \mathrm{~cm})$ de uma parcela inventariada implica na medição de um número excessivamente grande de plantas. $\mathrm{O}$ oposto acontece quando se medem somente indivíduos com DAP $\geq$ $10 \mathrm{~cm}$. Em relação à altura das plantas, o DAP é medido mais fácil e rapidamente, o que simplifica os levantamentos, além de possibilitar maior precisão e exatidão das estatísticas. Além disso, a partir do DAP se obtém a área basal, variável de maior significância ecológica da vegetação. Desta forma, a medição de indivíduos com $\mathrm{DAP} \geq 5 \mathrm{~cm}$ dentro da parcela do inventário mostra-se como o critério que permite melhor conciliar a caracterização do estágio sucessional com a operacionalidade desse inventário.

A amostragem dos indivíduos com DAP $\geq$ $5 \mathrm{~cm}$ (ou seu equivalente em circunferência) tem sido adotada por muitos trabalhos que objetivam a caracterização de estágios sucessionais (exemplos: DRUMOND e NETO, 1999; SILVA et al., 2004; MANTOVANI et al., 2005; SCHORN e GALVÃO, 2006; LIEBSCH et al., 2007; MARAGON et al., 2007). Esse valor também aproxima-se do critério que prevê a amostragem dos indivíduos arbóreos com CAP (circunferência a altura do peito) igual ou superior a $20 \mathrm{~cm}(6,36 \mathrm{~cm}$ de DAP $)$, definido pela Resolução CONAMA n02/1994, que estabelece os parâmetros para definir os estágios sucessionais no estado do Paraná, sendo esta a única resolução que apresenta um critério definido.

\section{Caracterização dos estágio sucessionais}

Utilizando-se o critério de amostragem como DAP $\geq 5 \mathrm{~cm}$, buscou-se indentificar quais valores, para os parâmetros estabelecidos pela Resolução no 04/1994 do CONAMA, conseguem melhor caracterizar e discriminar os estágios suces- sionais (Tabela 2).

Os valores médios de diâmetro, altura total e área basal apresentaram um padrão de crescimento ao longo do processo sucessional, com grande amplitude de resultados em todos os estágios. Já para a variável densidade (indivíduos/ha), não foi verificado um comportamento crescente dos valores médios em relação à idade da vegetação, como observado nos demais descritores, uma vez que a maior densidade (2.341 indivíduos/ha) ocorreu no estágio Arbóreo Pioneiro (Tabela 2).

O crescimento ao longo do processo sucessional dos valores médios de diâmetro, altura total e área basal espelha a diversidade de gerações, formas de vida e a complexidade estrutural que ocorre ao longo do tempo, consistente com a classificação estrutural e funcional de florestas secundárias discutida por Budowski (1965) e Clark (1996). Já o comportamento apresentado pela variável densidade (indivíduos/ha) foi também observado por outros autores como Oliveira (2002) na Mata Atlântica, e por Aide et al. (2000) e Chinea (2002) em outras formações florestais secundárias.

O valor da área basal novamente se destacou entre as variáveis analisadas, no sentido de melhor discriminar os estágios como Arbustivo, Arvoretas e Arbóreo Pioneiro. Além disso, a área basal mostra-se como a variável mais consistente do ponto de vista biológico, uma vez que representa o potencial de ocupação espacial do sítio. Esta tem sido também a principal medida de dominância usada em trabalhos que objetivam avaliar estágios sucessionais com diferentes idades após distúrbio no Bioma Mata Atlântica (TABARELI e MANTOVANI, 1999; OLIVEIRA, 2002; OLIVEIRA et al. 2006; LIEBSCH et al. 2007). Apesar disso, mesmo essa variável tem o uso limitado pela existência da expressão "até" na Resolução n”04/1994 do CONAMA (Tabela 1). Pode-se verificar através dos valores de amplitude, e mesmo nos valores médios, que os valores limites estabelecido pela Resolução nº4/1994 do CONAMA são facilmente ultrapassados, principalmente nos estágios Arbóreo Pioneiro e Arbóreo Avançado (Tabela 2).

A Tabela 3 apresenta dois cenários de reavaliação dos valores estabelecidos pela Resolução no04/1994 do CONAMA, propostos com base na avaliação das 160 parcelas levantadas neste estudo. No cenário A, foram estabelecidos ajustes nos valores definidos na atual resolução, enquanto que no cenário B houve uma nova proposta para definição do estágio inicial, médio e avançado de regeneração. 
TABELA 2: Parâmetros estruturais: Diâmetro a altura do peito (DAP) médio, altura total média, área basal $(\mathrm{AB})$ e densidade (Número de indivíduos por hectare), avaliados em estágios sucessionais de diferentes idades no Bioma Mata Atlântica nas regiões Sul e Sudeste do Brasil.Valores entre parênteses representam a amplitude dos valores levantados.

TABLE 2: Structural parameters: diameter at breast height (DBH), total average height, basal area (BA) and density (number of individuals per hectare), evaluated in successional stages of different ages in 'Mata Atlântica' forest in southern and southeastern Brazil. Values in parentheses are the range of parameters obtained.

\begin{tabular}{|c|c|c|c|c|c|c|}
\hline Estágio sucessional & $\begin{array}{l}\text { Idade } \\
\text { média } \\
\text { (anos) }\end{array}$ & $\begin{array}{l}\operatorname{DAP}^{(1)} \\
(\mathrm{cm})\end{array}$ & $\begin{array}{c}\text { DAP } \\
\text { médio } \\
(\mathrm{cm})\end{array}$ & $\begin{array}{l}\text { Altura } \\
\text { média } \\
(\mathrm{m})\end{array}$ & $\begin{array}{c}\text { Área basal } \\
\mathrm{m}^{2} / \mathrm{ha}\end{array}$ & $\begin{array}{c}\text { Densidade } \\
\text { indivíduos/ha }\end{array}$ \\
\hline \multicolumn{7}{|l|}{ Neste levantamento } \\
\hline Arbustivo & 5 & \multirow{4}{*}{$\geq 5$} & $\begin{array}{c}6,5 \\
(5,0-8,5)\end{array}$ & $\begin{array}{c}4,4 \\
(2,0-6,8)\end{array}$ & $\begin{array}{c}2,3 \\
(0,1-5,8)\end{array}$ & $\begin{array}{c}711 \\
(50-2.350)\end{array}$ \\
\hline Arvoretas & 11 & & $\begin{array}{c}8,1 \\
(6,1-10,3)\end{array}$ & $\begin{array}{c}6,0 \\
(4,2-10,0)\end{array}$ & $\begin{array}{c}10,0 \\
(4,4-17,8)\end{array}$ & $\begin{array}{c}1.573 \\
(200-3.200)\end{array}$ \\
\hline Arbóreo Pioneiro & 19 & & $\begin{array}{c}10,2 \\
(7,9-16,0)\end{array}$ & $\begin{array}{c}7,9 \\
(5,4-10,5)\end{array}$ & $\begin{array}{c}23,4 \\
(16,3-36,5)\end{array}$ & $\begin{array}{c}2.341 \\
(1.200-4.100)\end{array}$ \\
\hline Arbóreo Avançado & 36 & & $\begin{array}{c}12,7 \\
(9,9-18,4)\end{array}$ & $\begin{array}{c}9,1 \\
(7,1-12,1)\end{array}$ & $\begin{array}{c}38,4 \\
(18,2-60,4)\end{array}$ & $\begin{array}{c}2.237 \\
(950-3.900)\end{array}$ \\
\hline \multirow{3}{*}{ Tabareli e Mantovani (1999) } & 10 & \multirow{3}{*}{$\geq 3,2$} & - & - & 5,0 & 1.280 \\
\hline & 18 & & - & - & 23,4 & 3.325 \\
\hline & 40 & & - & - & 33,4 & 2.735 \\
\hline \multirow{3}{*}{ Oliveira (2002) } & 5 & \multirow{3}{*}{$\geq 2,5$} & 4,7 & 3,7 & 5,6 & 1.915 \\
\hline & 25 & & 7,5 & 7,0 & 26,3 & 2.784 \\
\hline & 50 & & 9,6 & 8,8 & 32,4 & 2.273 \\
\hline \multirow{3}{*}{ Oliveira et al. (2006) } & 7 & \multirow{3}{*}{$\geq 0,2^{(2)}$} & 1,5 & - & 2,5 & 17.285 \\
\hline & 15 & & 2,1 & - & 11,6 & 18.500 \\
\hline & 20 & & 3,0 & - & 37,6 & 23.702 \\
\hline \multirow{2}{*}{ Liebsch et al. (2007) } & 20 & \multirow{2}{*}{$\geq 4,8$} & - & - & 21,5 & 1.890 \\
\hline & 80 & & - & - & 34,8 & 3.006 \\
\hline
\end{tabular}

${ }^{(1)} \mathrm{DAP}=$ Diâmetro a altura do peito do levantamento. ${ }^{(2)} \mathrm{DNS}=$ Diâmetro a altura do solo.

TABELA 3: Propostas de alteração dos parâmetros para caracterização da vegetação secundária nos estágios de regeneração para o estado de Santa Catarina.

TABLE 3: Proposals to review the regulation parameters for secondary forest classification in Santa Catarina state.

\begin{tabular}{cccc}
\hline Parâmetros & \multicolumn{3}{c}{ Estágio de Regeneração } \\
\cline { 2 - 4 } & Cenário A & Médio & Avançado \\
\hline Fisionomia & herbáceo/arbustiva & arbustiva/arvoretas & arbórea \\
Número de estratos & 1 & 1 a 2 & $\geq 2$ \\
Área Basal $\left(\mathrm{m}^{2} / \mathrm{ha}\right)$ & $\leq 5$ & $5 \mathrm{a} 18$ & $\geq 18$ \\
Média da amplitude dos diâmetros $(\mathrm{cm})$ & $\leq 8$ & $8-12$ & $\geq 12$ \\
Altura média $(\mathrm{m})$ & $\leq 6$ & $6 \mathrm{a} 10$ & $\geq 10$ \\
\hline Fisionomia & Cenário B & & \\
\hline Número de estratos & arbustiva/arvoretas & arbórea pioneira & arbórea avançada \\
Área Basal $\left(\mathrm{m}^{2} /\right.$ ha) & 1 a 2 & $\geq 2$ & $\geq 3$ \\
Altura média $(\mathrm{m})$ & $\leq 15$ & 15 a 30 & $\geq 30$ \\
Média da amplitude dos diâmetros $(\mathrm{cm})$ & $\leq 10$ & $10-15$ & $\geq 15$ \\
\hline
\end{tabular}


Os resultados do cenário A permitiram contornar em parte as deficiências de aplicação da atual resolução, o que pode ser observado na Figura 2b, através da avaliação da número de parcelas que se enquadraram dentro da definição dos estágios esperados, representando $93 \%$ para o estágio inicial, $90 \%$ para o estágio médio e $89 \%$ para o estágio avançado, considerando-se os valores de área basal.

No cenário B, é sugerida a exclusão da altura total média como variável para a classificação dos estágios, por conta de sua reduzida contribuição na discriminação desses estágios (Tabela 3). Esse cenário também apresentou grande porcentagem de correspondência das parcelas levantadas nos respectivos estágios de regeneração esperados, considerando-se os valores para área basal, representando $94 \%$ para o estágio inicial, $85 \%$ para o estágio médio e $83 \%$ para o estágio avançado. (Figura 2c).

Todos os resultados apresentados reforçam a necessidade de revisão de quais parâmetros devem ser adotados para caracterização, bem como de uma reavaliação dos valores estabelecidos pela Resolução nº4/1994 do CONAMA. No cenário A, onde foi mantida a proposta de caracterização da atual resolução, foi possível melhorar o grau de correspondência na classificação dos estágios de regeneração através de ajustes nos valores atualmente propostos.

A segunda proposta (cenário B), por sua vez, implica uma redefinição do que a Resolução n04/1994 do CONAMA propõe como estágio inicial, médio e avançado de regeneração, e é fundamentada no processo ecológico de sucessão natural (FANTINI e SIMINSKI, 2005). Neste cenário, o estágio inicial de regeneração passa a incorporar os estágios sucessionais arbustivo e de arvoretas, sendo caracterizado principalmente por espécies pioneiras arbustivas e indivíduos arbóreos esparsos. A mudança do estágio inicial para médio é marcada por uma significativa diferença estrutural e qualitativa, que é a formação efetiva de um dossel contínuo, a partir da dominâcia na fitofisionomia de indivíduos arbóreos, com predominância de poucas espécies. Por sua vez, a mudança do estágio médio para avançado é marcado pelo aumento da diversidade de espécies e complexidade estrutural, com definição dos estratos da floresta (sinusias), com predomínio de espécies oportunistas e climáxicas.

Essa proposta busca incorporar ao processo de classificação da vegetação elementos marcantes do processo de sucessão, o que amplia a possibilidade de identificação dos estágios de regeneração de a) Limites atuais da Resolução nº4/1994 do CONAMA

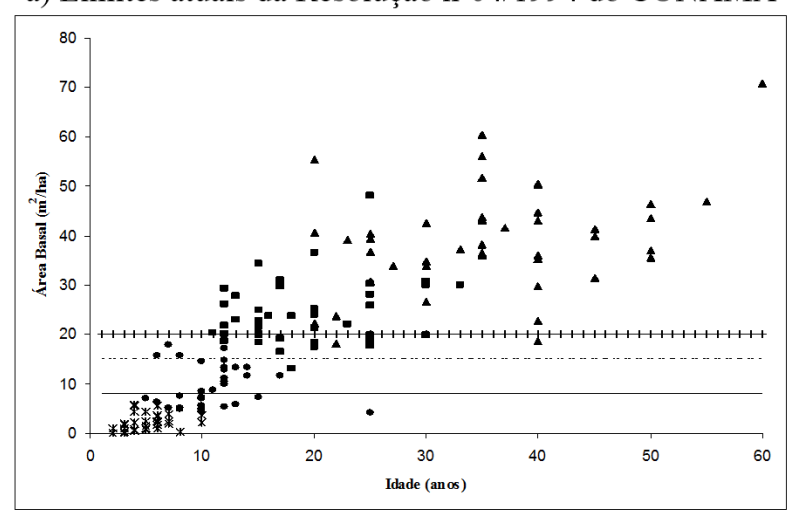

b) Nova proposta, Cenário A

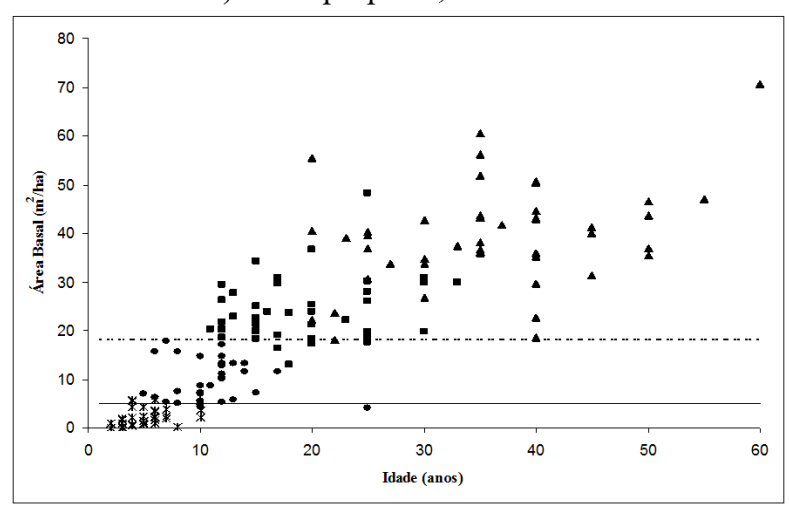

c) Nova proposta, Cenário B

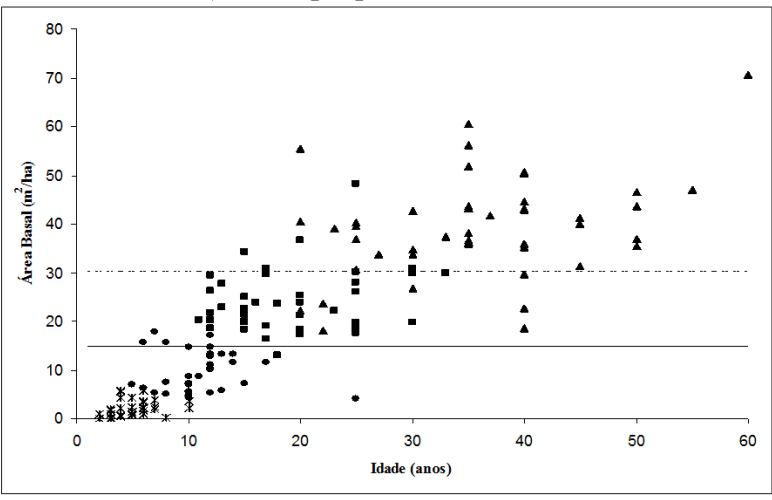

\begin{tabular}{|c|c|c|c|}
\hline Arbustivo & - Arvoretas & - Arbóreo Pioneiro & Artóreo Avançado \\
\hline _ inicial & -....... médio & , avançado & \\
\hline
\end{tabular}

FIGURA 2: Distribuição das parcelas dos quatros estágios de sucessão considerando os valores limites de área basal para os três estágios de regeneração da Mata Atlântica em Santa Catarina, em diferentes cenários de avaliação.

FIGURE 2: Plots distribution of four successional stages in the three stages of regeneration of 'Mata Atlântica' in Santa Catarina, considering different scenarios of basal area limits. 
forma mais precisa por parte dos profissionais que fazem os levantamentos.

\section{CONCLUSÕES}

O aparato legal exige a classificação dos estágios da sucessão através de estatísticas obtidas a partir do inventário da vegetação. Ao mesmo tempo, suas regulamentações possibilitam a obtenção de resultados divergentes para diferentes avaliações no mesmo local, produzindo insegurança quanto ao seu objetivo.

Os resultados apresentados neste trabalho apontam as seguintes sugestões para a uniformização dos procedimentos dos inventários florestais para fins de classificação da vegetação em estágios de regeneração: 1) utilização do diâmetro a altura do peito (DAP) como a principal variável a ser medida em campo; 2) inclusão de todos os indivíduos com DAP igual ou superior a $5 \mathrm{~cm}$ na amostragem; 3) utilização da área basal $\left(\mathrm{m}^{2} / \mathrm{ha}\right)$ como o principal parâmetro para a definição dos estágios.

Com relação aos valores dos parâmetros para a classificação propriamente dita, as duas propostas apresentadas neste trabalho possuem objetivos e implicações distintas, porém, convergem no sentido de necessidade de rediscussão da Resolução $n^{\circ} 04 / 1994$ do CONAMA e suas regulamentações. No caso do cenário B, é preciso ter claro que a proposta também implica uma reavaliação do atual grau de permissão de intervenção no Bioma Mata Atlântica para o estado de Santa Catarina, o que amplia a necessidade de rediscussão da Resolução vigente não apenas do ponto de vista ecológico, mas, e talvez principalmente, político e social.

\section{AGRADECIMENTOS}

Ao Núcleo de Pesquisas em Florestas Tropicais da UFSC, pelo apoio logístico; ao CNPq, pela concessão de bolsa de Doutorado; à FAPESC pelo apoio financeiro; à Fatma (Autorização de Pesquisa $n^{\circ}$ 009/2007/GERUC/DPEC), Ecopef e Epagri (escritórios de Anchieta, Garuva e Três Barras) pelo apoio no desenvolvimento da pesquisa; aos Drs. Ademir Reis e Ademir Roberto Ruschel, pelo auxílio na identificação do material botânico.

\section{REFERÊNCIAS BIBLIOGRÁFICAS}

AIDE, T.M. et al. Forest regeneration in chronosequence of tropical abandoned pastures: implications for restoration ecology. Restoration Ecology, v.8, n.4, p.328-338, 2000.

ALVES, L.F.; METZGER, J.P. Forest regeneration in secondary forest areas at Morro Grande Forest Reserve, Cotia, SP. Biota Neotropica, v.6, n.2, 2006. disponível em http://www.biotaneotropica. org.br/v6n2/pt/abstract?article+bn00406022006. Acesso em 15 de abr. 2008.

AMARAL, M. V. F. et al. Avaliação e compação de métodos de classificação de imagens de satélites para o mapeamento de estádios de sucessão florestal. Revista Árvore, v. 33, p. 575-582, 2009.

APG II. An update of the Angiosperm Phylogeny Group classification for the orders and families of flowering plants: APG II. Botanical Journal of the Linnean Society. 141(4), p. 399-436. 2003.

BRASIL. Decreto $\mathbf{n}^{\circ} \mathbf{7 5 0}$ de $\mathbf{1 0}$ de fevereiro de 1993. Disponível em: $<(\mathrm{http}: / / \mathrm{www}$.planalto. gov.br/ccivil_03/decreto/1990-1994/D750.htm)> Acesso em: 15 janeiro de 2009.

BRASIL. Lei $n^{\circ} \mathbf{1 1 . 4 2 8}$ de 22 de dezembro de 2006. Dispõe sobre a utilização e proteção da vegetação nativa do Bioma Mata Atlântica e dá outras providências. Disponível em: (http://www. planalto.gov.br/ccivil/_Ato2004-2006/2006/Lei/ L11428.htm) > Acesso em: 18 de fevereiro de 2008. BRASIL. Decreto $\mathrm{n}^{0} \mathbf{6 . 6 6 0}$, de 21 de novembro de 2008. Disponível em: $<$ ( http://www.planalto.gov. br/ccivil_03/Ato2007-2010/2008/Decreto/D6660. htm\#art51)> Acesso em: 15 janeiro de 2009.

BUDOWSKI, G. Distribution of tropical American Rain Forest trees in the light of successional process. Turrialba, v.15, p.40-45, 1965.

CHINEA, J.D. Tropical forest succession on abandoned farms in the Humacao Municipality of eastern Puerto Rico. Forest Ecology and Management, v.167, p.195-207, 2002.

CINTRA, D.P. et al. Classificação de estágios sucessionais florestais através de imagens Ikonos no Parque Estadual da Pedra Branca, RJ. In: XIII Simpósio Brasileiro de Sensoriamento Remoto. Anais. Florianópolis, Brasil, 21-26 abril 2007, INPE, p.1627-1629.

CLARK, D.B. Abolishing virginity. Journal of Tropical Ecology, v.12, p.735-739, 1996.

CONAMA. Conselho Nacional de Meio Ambiente. Resolução n 04, de 4 de maio de 1994. Disponível em: $\quad<$ http://www.mma.gov.br/port/conama/ legiabre.cfm?codlegi=145)> Acesso em: 15 janeiro de 2009.

CONAMA. Conselho Nacional Do Meio Ambiente. Resolução $\mathbf{N}^{\circ}$ 388, de 23 de fevereiro de 2007. 
Dispõe sobre a convalidação das resoluções que definem a vegetação primária e secundária nos estágios inicial, médio e avançado de regeneração da Mata Atlântica para fins do disposto no art. 4o $\S 1$ o da Lei no $11.428 / 2006$. Disponível em: $<($ http://www.mma.gov.br/port/conama/legiabre. cfm?codlegi $=529)>$ Acesso em: 15 janeiro de 2009. DRUMOND, M.A.; NETO, J.A.A.M. Composições florística e fitossociológica de uma mata secundária de um trecho da Mata Atlântica. Ciência Rural, Santa Maria, v. 29, n.4, 1999.

FANTINI, A.C.; SIMINSKI, A. Recuperação natural da vegetação após uso agrícola da terra no litoral de Santa Catarina. In: Anais do VI Congresso Simpósio Nacional e Congresso latino Americano de Recuperação de áreas degradadas, 2005, Curitiba/PR. 2005. p.147-155.

FINEGAN, B. Pattern and process in neotropical secondary rain forests: the first 100 years of sucession. Tree, v.11, n.3, p.119-124, 1996.

FONSECA, R.C.B.; FONSECA, I.C.B. Utilização de métodos estatísticos multivariados na caracterização do mosaico sucessional em floresta semidecídual. Revista Árvore, Viçosa, v.28, n.3, p.351-359, 2004.

GUARIGUATA, M.R.; OSTERTAG, R. Neotropical Secondary Forest succession: changes in structural and functional characteristics. Forest Ecology and Management v.148, p.185-206, 2001.

JASTER, C.B. A estrutura como indicadora do nível de desenvolvimento sucessional de comunidades arbóreas da restinga Uma proposta metodológica. 2002. Tese (Doutorado em Ciências Florestais) Universidade Federal do Paraná, Curitiba, 2002.

KLEIN, R.M. Mapa fitogeográfico do Estado de Santa Catarina. Itajaí: Herbário Barbosa Rodrigues, 1978. 24 p.

KLEIN, R.M. Ecologia da Flora e Vegetação do Vale do Itajaí. Sellowia, Itajaí, v. 32, n. 32, p.164369, 1980.

LANA, J. M. et al. Análise dos estágios de sucessão de áreas de Mata Atlântica sob a influência de plantações florestais, Vale do Rio Doce, Minas Gerais, Brasil. Revista Árvore, Viçosa, v. 34, p. 733-743, 2010.

LIEBSCH, D. et al. Florística e estrutura de comunidades vegetais em uma cronoseqüência de Floresta Atlântica no Estado do Paraná, Brasil. Acta bot. bras. v.21, n.4, p.983-992, 2007.

LIEBSCH, D. et al. How long does the Atlantic Rain Forest take to recover after a disturbance? Changes in species composition and ecological features in the secondary succession.. Biological Conservation, v.141, p.1717-1725, 2008.

MANTOVANI, M. et al. Diversidade de espécies e estrutura sucessional de uma formação secundária da floresta ombrófila densa. Scientia Forestalis, Piracicaba, v. 67, p.14-26, 2005.

MARAGON, L.C. et al. Estrutura fitossociológica e classificação sucessional do componente arbóreo de um fragmento de floresta estacional semidecidual, no município de Viçosa, Minas Gerais. Cerne, Lavras, v.13, n. 2, p.208-221, 2007.

MAUSEL, P. et al. Spectral identification of succession stages following deforestation in the Amazon. Geocarto Int. v.8, p.61-72, 1993.

MORAN, E.F.; BRONDÍZIO, E.S. Land-use change after deforestation in Amazônia. In: LIVERMAN, D. et al. People and Pixels: Linking Remote Sensing and Social Science. National Academy Press, Washington, DC, 1998. pp.94-120.

OLIVEIRA, R.R. Ação antrópica e resultantes sobre a estrutura e composição da Mata Atlântica na Ilha Grande, RJ. Rodriguésia, v.53, n.82, p.33-58, 2002. OLIVEIRA, F.X. et al. Comparações florísticas e estruturais entre comunidades de Floresta Ombrófila Aberta com diferentes idades, no Município de Areia, PB, Brasil. Acta Botânica Brasilica, v.20, n.4, p.861-873, 2006.

QUEIROZ, M.H. Approche Phytoécologoque et Dynamique des Formations Végetales Secondaires Développées Après Abandon dês Activités Agricoles, dans lê Domaine de la Fôret Ombrophile Dense de Versant (Fôret Atlantique) à Santa Catarina - Brésil. 1994. 251 f. Tese (doutorado) - École Nationale du Génie Rural, des Eaux et des Forêts, Nancy - França, 1994.

RAMOS, A. J. K.; BOLDO, E. Diversidade florística e aspectos fitossociológicos de formações florestais em estágio sucessional secundário na floresta ombrófila mista, município de Caxias do Sul-RS. Revista Brasileira de Agroecologia, v.2, n.1, p.111-116, 2007.

SALDARRIAGA, J.G. et al. Longterm chronosequence of forest succession in the Upper Rio Negro of Colombia and Venezuela. Journal of Ecology. v.76, p.938-958, 1988.

SCHORN, L.A.; GALVAO, F. Dinâmica da regeneração natural em três estágios sucessionais de uma floresta ombrófila densa em Blumenau, SC. Floresta, Curitiba, v.36, n.1, p.59-74, 2006.

$\mathrm{SCHUCH}$, C. Potencialidades da produção de madeira serrada a partir de três espécies 
da floresta secundária litorânea catarinense em condições de plantio e em área de floresta regenerada naturalmente. 2010. 80f. Dissertação (Mestrado em Recursos Genéticos Vegetais) - Universidade Federal de Santa Catarina, Florianópolis, 2010.

SILVA, C.T. et al. Avaliação temporal da florística arbórea de uma floresta secundária no município de Viçosa, Minas Gerais. Revista Árvore, Viçosa, v.28, n.3, p. 429-441, 2004.

SIMINSKI, A.; FANTINI, A.C. Classificação da Mata Atlântica do litoral catarinense em estádios sucessionais: ajustando a lei ao ecossistema. Floresta e Ambiente, Seropédica, v.11, n.2, p2025, 2004.

SIMINSKI, A. et al. Sucessão Florestal Secundária no município de São Pedro de Alcântara, litoral de Santa Catarina: estrutura e diversidade. Ciência Florestal, Santa Maria, v. 14, n. 1, p. 21-33, 2004.

SIMINSKI, A. A floresta do futuro: conhecimento, valorização e perspectivas de uso das formações florestais secundárias no estado de Santa Catarina. 2009, 153f. Tese (Doutorado em
Ciências), Universidade Federal de Santa Catarina, Florianópolis, 2009.

SIMINSKI, A. et al. Secondary Forest Succession in The Mata Atlantica, Brazil: Floristic and Phytosociologic Trends. ISRN Ecology, v. 2011, p. 1-19, 2011.

SOKAL, R. R.; ROHLF, F. J. Biometry: the principles and practice of statistics in biological research. 3rd edition. W. H. Freeman and Co.: New York. 1995. 887 p.

TABARELLI, M.; MANTOVANI, W. A regeneração de uma floresta tropical montana após corte e queima (São Paulo - Brasil). Revista Brasileira de Biologia, v.59, n.2, p.239-250, 1999.

VAN BREUGEL, M. Dynamics of secondary forests. 2007, 252f. Thesis (Doctor of Philosophy) -Wageningen University, Wageningen. 2007.

UHL, C. et al. Abandoned pastures in eastern Amazônia. I. Patterns of plant succession. Journal of Ecology, v.76, p.663-681, 1988.

WHITMORE, T.C. An introduction to Tropical Rain Forests. Second edition. New York. Oxford University Press. 1998. 282 p. 